\title{
Bovine immunoglobulin A (IgA)-binding activities of the surface-expressed Mig protein of Streptococcus dysgalactiae
}

\author{
Xin-Ming Song, ${ }^{1}$ Jose Perez-Casal, ${ }^{1}$ Michael C. Fontaine ${ }^{1}$ \\ and Andrew A. Potter ${ }^{1,2}$
}

\footnotetext{
1 Veterinary Infectious Disease Organization (VIDO), Saskatoon, Saskatchewan, Canada S7N 5E3

2 Canadian Bacterial Diseases Network, Calgary, Alberta, Canada
}

\author{
Author for correspondence: Andrew A. Potter. Tel: +1 306966 7484. Fax: +1 3069667478 . \\ e-mail: Potter@sask.usask.edu
}

\begin{abstract}
The Mig protein of Streptococcus dysgalactiae is a type III immunoglobulin G (IgG)-binding protein, expressing IgG- and $\alpha_{2}$-macroglobulin $\left(\alpha_{2}\right.$-M)-binding receptors. This study showed that the Mig protein also displays binding activities to bovine immunoglobulin A (B-IgA). Biotin-labelled bovine serum IgA bound immobilized recombinant Mig and $\alpha_{2}-M$ receptors derived from Mig, as well as the native Mig extracted from the surface of $S$. dysgalactiae strain SDG8 and the $\alpha_{2}-M$ receptor released from the isogenic mig mutant strain Mig8Mt, as determined by Western blotting and ELISA. There was no B-IgA binding activity to the immobilized IgG receptor derived from Mig or the proteins in the culture supernatant from the mig mutant strain Mig7-Mt, in which expression of Mig or Mig-related peptides on the cell surface was completely abolished. In a reciprocal experiment, biotin-labelled Mig was found to bind immobilized bovine serum IgA but not human IgA (H-IgA). The binding of Mig to bovine serum IgA was competitively inhibited by unlabelled Mig, intact and truncated $\alpha_{2}-M$ receptors, and bovine serum IgA, but not by the Mig-lgG receptor, H-IgA or B-IgG. The binding of Mig and partially purified bovine secretory IgA (B-sIgA) was also characterized by Western blotting. Membraneimmobilized B-slgA did not react with the biotin-labelled Mig, whereas soluble B-slgA showed binding activity to the immobilized $\alpha_{2}-M$ receptor of Mig. It is therefore concluded that the $11 \mathrm{kDa} \mathrm{N}$-terminal region of the $\alpha_{2}-\mathrm{M}$ receptor of the $S$. dysgalactiae Mig protein specifically binds soluble and immobilized bovine serum IgA, as well as soluble B-slgA. This is believed to be the first report of a B-IgA-binding protein in S. dysgalactiae.
\end{abstract}

Keywords: IgG, $\alpha_{2}$-macroglobulin, receptor, bovine mastitis

\section{INTRODUCTION}

Streptococcus dysgalactiae, the Lancefield serological group $\mathrm{C}$ bacterium, is one of the most common environmental pathogens capable of causing bovine mastitis, a disease responsible for large economic losses in the dairy industry. Normal methods of hygiene and antibiotic therapy have little effect in the prevention of $S$. dysgalactiae infections. In spite of its high prevalence, little is known about factors that contribute to the virulence of S. dysgalactiae (Calvinho et al., 1998).

Abbreviations: $\alpha_{2}-M, \alpha_{2}$-macroglobulin; AP, alkaline phosphatase; $B-$, bovine (immunoglobulins); $\mathrm{H}-$, human (immunoglobulins); slgA, secretory immunoglobulin A.
Therefore, looking for virulence factors expressed on the bacterial surface and using them as vaccine targets might be an effective way to prevent bovine mastitis associated with $S$. dysgalactiae infections.

A few surface-expressed proteins in S. dysgalactiae have been characterized. The list includes the $\alpha_{2}$-macroglobulin $\left(\alpha_{2}-\mathrm{M}\right)$ - and immunoglobulin G (IgG)-binding protein Mig (Jonsson \& Müller, 1994), the $\alpha_{2}-$ M-, albumin- and IgG-binding protein Mag (Jonsson et al., 1994), and fibrinogen- and IgG-binding M-like proteins (Vasi et al., 2000). Some $S$. dysgalactiae surface receptors that bind to host-derived plasma and matrix proteins such as albumin, fibronectin, collagen, vitronectin and plasminogen have also been reported (Calvinho et al., 1998). Recently, the role of Mig in the virulence of $S$. 
dysgalactiae has been investigated in our laboratory. Our research indicates that the Mig protein is involved in resisting phagocytosis by bovine neutrophils (PMNs) in the presence of bovine serum (Song et al., 2001). Thus, the Mig protein, an M-like protein, is considered a potential virulence factor of $S$. dysgalactiae. In bovine mastitis, the mucosal defence system in the mammary gland plays a major role in the prevention of infection. Since immunoglobulin A (IgA) is the predominant class of immunoglobulin present on mucosal surfaces, and constitutes an important defence mechanism against microbial infections, IgA-binding receptors expressed by bacteria might be involved in the development of mastitis by binding IgA and helping the micro-organism evade the immunological surveillance of the host. In group A and B human streptococcal pathogens, speciesspecific human-IgA (H-IgA)-binding receptors have been reported. With the exception of SibA (Fagan et al., 2001), most IgA-binding proteins of group A streptococcal strains are $\mathrm{M}$ or $\mathrm{M}$-like proteins that may play a role in protection against phagocytosis. These include the proteins Arp4 (Johnsson et al., 1994; Lindahl \& Åkerström, 1989), Sir22 (Stenberg et al., 1994) and ML2.2 (Bessen, 1994). IgA-binding receptors were also found in Streptococcus agalactiae, including Bac (Hedén et al., 1991) and $\beta$-antigen proteins (Cleat \& Timmis, 1987; Russell-Jones et al., 1984). Although all of them show specific binding activities to $\mathrm{H}-\mathrm{IgA}$, the group A streptococcal receptors bind both serum and secretory $\operatorname{Ig} \mathrm{A}(\mathrm{s} \operatorname{Ig} \mathrm{A})$, whereas the group B streptococcal receptor binds mainly serum IgA (Lindahl et al., 1990). Other H-IgA-binding receptors were also reported in Streptococcus pneumoniae, including a $52 \mathrm{kDa}$ protein (Serhir et al., 1995) and a $59 \mathrm{kDa}$ protein SpsA that specifically binds H-IgA secretory component (Hammerschmidt et al., 1997). One of the possible roles of the IgA-binding proteins appears to be protection against phagocytosis, since binding of $\mathrm{H}$-IgA to receptors in Streptococcus pyogenes has been found to interfere with bacterial adhesion to the host cells (Fluckiger et al., 1998).

Since $S$. dysgalactiae is a major bovine mastitis-causing pathogen and the bovine mammary gland mucosal defence system plays an important role in protection against infections, we investigated the presence of bovine IgA-binding receptors in $S$. dysgalactiae strains isolated from cases of bovine mastitis. Here we report that the surface-expressed Mig protein, a well-characterized $\alpha_{2}$ M- and IgG-binding protein of $S$. dysgalactiae, exhibits specific binding activities to serum and secretory bovine $\operatorname{Ig} \mathrm{A}$ (B-IgA and B-sIgA, respectively). We used a Migexpressing wild-type strain, two isogenic mig mutant strains, purified recombinant Mig, and Mig-derived peptides, to test B-IgA-binding activities. We were able to identify the IgA-binding domain in Mig and map it to the $11 \mathrm{kDa} \mathrm{N}$-terminal region of the $\alpha_{2}-\mathrm{M}$ receptor portion of Mig. This finding consolidated our conclusion that the Mig protein possesses multiple binding activities, and is a potential virulence factor of $S$. dysgalactiae strains causing bovine mastitis.

\section{METHODS}

Bacterial strains and media. The Lancefield group C streptococcal isolate $S$. dysgalactiae ATCC 43078, renamed SDG8 in this study, was obtained from the American Type Culture Collection. The mig mutant strain Mig8-Mt derived from S. dysgalactiae SDG8 was described previously (Song et al., 2001). The group A streptococcal S. pyogenes strain 'M5 Manfredo' was originally obtained from the Memphis VA Hospital Culture Collection, University of Tennessee, Memphis, TN, USA, and kindly provided by Professor M. A. Kehoe, Newcastle University, UK. The Lancefield group B streptococcus S. agalactiae strain SB35, expressing the H-IgAbinding protein Bac (Hedén et al., 1991), was kindly provided by Dr G. Lindahl, Lund University, Lund, Sweden. The Escherichia coli strains DH5 $\alpha[\phi 80 \mathrm{~d} l a c Z \Delta \mathrm{M} 15$, recA1 endA1 gyrA96 thi-1 hsdR17 supE44 relA1 deoR, $\Delta(\operatorname{lacZYA-\operatorname {argF})}$

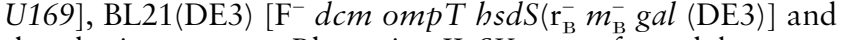
the cloning vector pBluescript II SK were from laboratory collections. E. coli XL10-Gold $\operatorname{Kan}^{r}[\Delta(m c r A) 183 \Delta(m c r C B-$ hsdSMR-mrr) 173 end A1 supE44 thi-1 recA1 gyrA96 relA1 lac Hte $\left(\mathrm{F}^{\prime}\right.$ proAB lacl ${ }^{\mathrm{Q}} \mathrm{Z} \Delta \mathrm{M} 15$ Tn10 Tn5 Amy)] was obtained from Stratagene. The expression vector $\mathrm{pET}-15 \mathrm{~b}$, carrying an $\mathrm{N}$-terminal $6 \times$ His-Tag was obtained from Novagen. The temperature-sensitive shuttle vectors pEU904 and $\mathrm{pG}^{+}$host 9 were generous gifts from Dr J. R. Scott, Emory University, Atlanta, GA, USA, and Dr E. Maguin, Institut National de la Recherche Agronomique (INRA), France, respectively. The $E$. coli strain TG1 (dev) $\left[\mathrm{F}^{\prime}\right.$ traD36 lacl ${ }^{\mathrm{a}} \Delta($ lac Z $) \mathrm{M} 15$ proA $^{+} B^{+} /$ supE $\Delta($ bsdM-mcrB) recA::tet thi $\Delta($ lac-pro $A B)$ repA:km] used as a host for $\mathrm{pG}^{+}$host 9 was also kindly provided by $\mathrm{Dr} \mathrm{E}$. Maguin.

Streptococcal strains were grown in Todd-Hewitt culture medium (Oxoid) or agar supplemented with $0.5 \%$ yeast extract (THY) at $37^{\circ} \mathrm{C}$ in a $5 \% \mathrm{CO}_{2}$ atmosphere. E. coli strains were cultured in Luria-Bertani (LB) medium. When required, antibiotics were added to the following concentrations: $50 \mu \mathrm{g}$ ampicillin $\mathrm{ml}^{-1} ; 50 \mu \mathrm{g}$ carbenicillin $\mathrm{ml}^{-1} ; 1 \mu \mathrm{g}$ erythromycin $\mathrm{ml}^{-1} ; 100 \mu \mathrm{g}$ kanamycin $\mathrm{ml}^{-1} ; 200 \mu \mathrm{g}$ rifampicin $\mathrm{ml}^{-1}$; and $200 \mu \mathrm{g}$ spectinomycin $\mathrm{ml}^{-1}$.

Immunoglobulins. Purified B-IgA and bovine $\operatorname{IgM}(\mathrm{B}-\operatorname{IgM})$ were obtained from Inter-Cell Technologies and Sigma, respectively. Human IgA (H-IgA) was obtained from Cappel. Bovine $\operatorname{IgG}_{1}\left(B-\operatorname{IgG}_{1}\right)$ and $\operatorname{IgG}_{2}\left(\mathrm{~B}-\operatorname{IgG}_{2}\right)$ were from Jackson ImmunoResearch Laboratories. Rabbit anti-B-sIgA was obtained from Nordic Immunology. Alkaline phosphatase (AP)conjugated goat anti-B-IgG $(\mathrm{H}+\mathrm{L})$ was obtained from Kirkegaad \& Perry Laboratories. Polyclonal antibodies against Mig raised in rabbits and purification of specific Mig IgG antibodies have been described previously (Song et al., 2001).

DNA manipulations. Plasmid DNA was prepared with DNA preparation kits from either Qiagen or Sigma. S. dysgalactiae genomic DNA was extracted as described previously (Song et al., 2001). Either $\mathrm{CaCl}_{2}$-treated (Sambrook et al., 1989) or PEG-treated (Kurien \& Scofield, 1995) E. coli cells were used for transformation. Oligonucleotides other than those specified, used for amplification of the mig structural gene and the $\alpha_{2}-\mathrm{M}$ - and IgG-binding regions have been described previously (Song et al., 2001). Restriction endonucleases, Taq DNA polymerase and dNTPs were obtained from Amersham Pharmacia Biotech. T4 DNA ligase was from USBiological. PCR amplification was run for 35 cycles of $45 \mathrm{~s}$ at $94^{\circ} \mathrm{C}, 45 \mathrm{~s}$ at $55^{\circ} \mathrm{C}$ and $1 \mathrm{~min}$ at $72{ }^{\circ} \mathrm{C}$ with an initial step of $3 \mathrm{~min}$ at $95^{\circ} \mathrm{C}$ for denaturation, followed by a final extension of $5 \mathrm{~min}$ at $72{ }^{\circ} \mathrm{C}$. The Geneclean Spin Kit (Bio 101) and UltraClean 

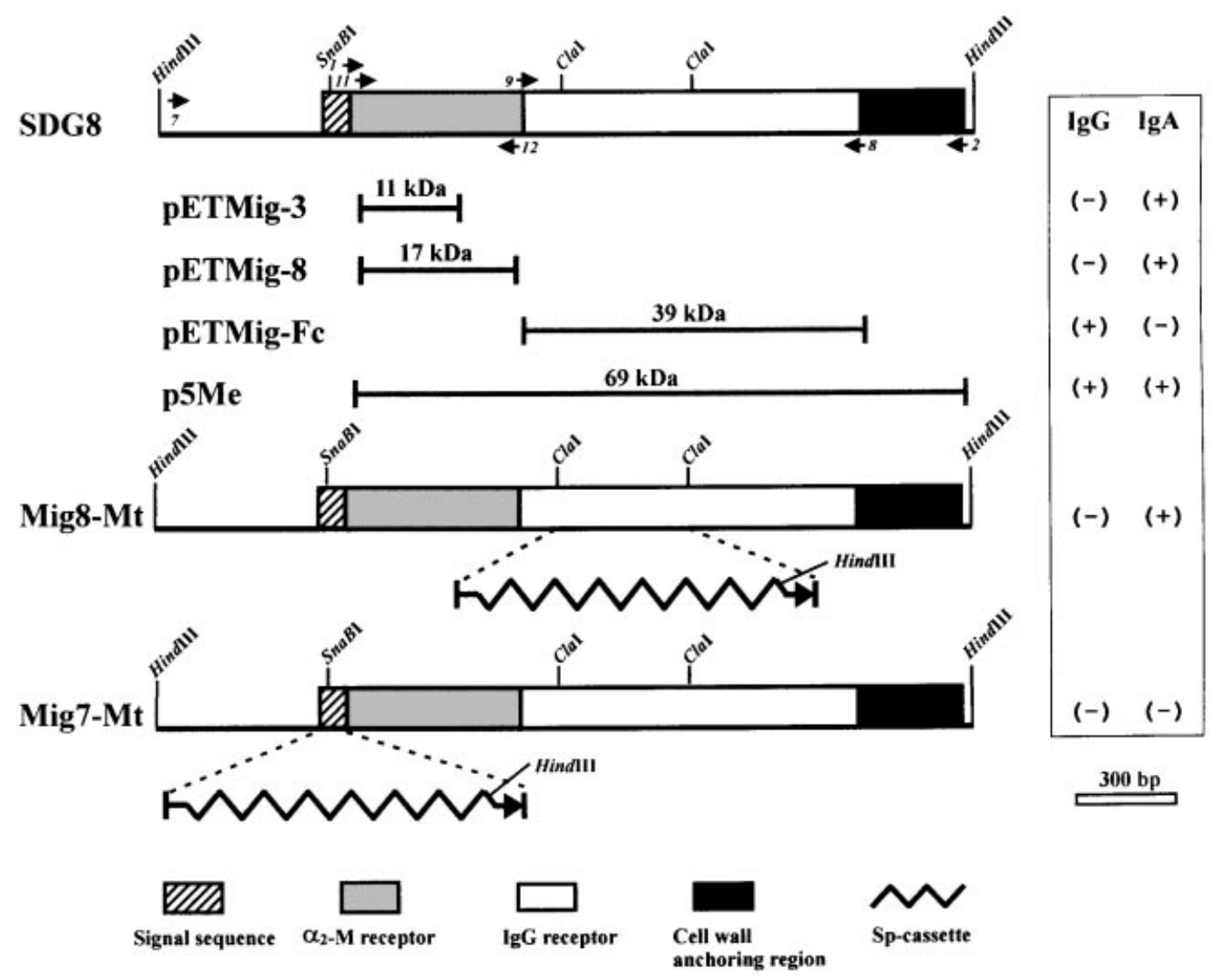

Fig. 1. Schematic maps of the mig gene in the wild-type strain SDG8, and isogenic mig mutant strains Mig8-Mt and Mig7Mt. The construction and chromosomal map of the Mig8-Mt strain has already been described (Song et al., 2001) and is presented here to allow comparison. The locations of the PCR primers used to construct plasmids and generate probes are indicated with arrows. The numbers on the arrows correspond to the Mig primers described previously (Song et al., 2001). Restriction enzyme sites used for strain construction and Southern blots are marked. The names of the plasmids, and the coding location and mass of Mig-related protein products encoded, are represented below the map for the wildtype SDG8 strain. The block symbols indicate regions of the Mig protein, and the zig-zag line indicates the Sp-cassette used for mutagenesis. On the right side, the binding activities to AP-conjugated goat IgG (IgG) and biotin-labelled bovine serum $\lg A(\operatorname{IgA})$ of the purified and culture supernatant proteins of the mig mutant strains are indicated.

GelSpin DNA Purification Kit (Mo Bio Laboratories) were used to purify PCR products or plasmid DNA fragments from agarose gels when needed.

Construction of plasmids and strains. The plasmid p $5 \mathrm{Me}$ expressing the mature Mig protein, and the isogenic mig mutant strain Mig8-Mt (Fig. 1) expressing $\alpha_{2}-\mathrm{M}$ receptors only in the culture medium, have been described previously (Song et al., 2001). To construct plasmids expressing intact and truncated $\alpha_{2}$-M-binding receptors, a $0.5 \mathrm{~kb}$ fragment encoding the $\alpha_{2}$-M-binding region of Mig was amplified with Mig-11 and Mig-12 primers (Fig. 1) from two templates. The entire $\alpha_{2}-$ $M$ receptor region was amplified from $S$. dysgalactiae SDG8 genomic DNA, digested with NdeI and BamHI, and cloned into the expression vector pET-15b to generate pETMig-8. The truncated version of the $\alpha_{2}-\mathrm{M}$ receptor of Mig was amplified from pKSMig-3. This plasmid carries a point mutation in the $\alpha_{2}-\mathrm{M}$ coding region, resulting in a premature stop codon (data not shown). The amplified fragment was cleaved with NdeI and BamHI, and ligated to pET-15b to generate $\mathrm{pETMig}-3$. Finally, the IgG-binding receptor region of Mig was amplified from SDG8 genomic DNA with the Mig9 and Mig- 8 primers (Fig. 1) and cloned into pET-15b. One recombinant plasmid, pETMig-Fc, carrying a $1.1 \mathrm{~kb}$ insert, was selected for expression of the IgG-binding receptor protein.

To construct a $S$. dysgalactiae strain deficient in expression of the Mig protein on the cell surface, an approximately $1 \mathrm{~kb}$ fragment carrying the region upstream of the mig start codon and the entire $\alpha_{2}$-M-binding region was amplified from SDG8 genomic DNA with Mig-7 and Mig-12 primers (Fig. 1). This fragment was cloned into the BamHI and $\mathrm{XbaI}$ sites of pBluescript II SK. The resulting plasmid was named pMigmut1. After treatment with SnaBI, the linearized pMigmut-1 was ligated to the $1.2 \mathrm{~kb}$ aad 9 gene from pEU904 encoding resistance to spectinomycin, amplified with ad9-01 (5'TCGATAGCTTGCATGCCTGCAG-3') and aad9-02 (5'GAGGTCGACGGTATCGATAAGC-3') primers. The resulting plasmid, pMigmut-6, carries the aad 9 gene inserted immediately downstream of the Mig start codon. The insert in pMigmut-6 was cleaved with EcoRV and NotI, and cloned into $\mathrm{pG}^{+}$host 9 to generate pMigmut-7. This plasmid was transformed into SDG8, and allele-replacement of the chromosomal mig gene was performed as described previously (PerezCasal et al., 1993). Colonies resistant to spectinomycin and sensitive to erythromycin were isolated at $37^{\circ} \mathrm{C}$ and the strain was designated Mig7-Mt (Fig. 1). 
Southern blots. To characterize the mig mutant strain Mig7$\mathrm{Mt}$, probes specific to the mig IgG-binding region and to the spectinomycin-resistance cassette (Sp-cassette) were labelled with DIG-dUTP (Roche) by PCR with the Mig-9/Mig-8 and aad9-01/aad9-02 primers, respectively. Conditions for labelling, hybridization and detection were similar to those previously described (Song et al., 2001).

Expression and purification of proteins in E. coli. The Mig protein was expressed from p5Me in E. coli and purified with a B-IgG affinity column (Song et al., 2001). To express the intact and truncated forms of $\alpha_{2}-\mathrm{M}$ receptors of Mig, the plasmids pETMig-8 and pETMig-3 were transformed into $E$. coli BL21(DE3). Protein expression was induced by IPTG (Sigma) at a final concentration of $1 \mathrm{mM}$ from exponentialphase cultures, in LB broth for $5 \mathrm{~h}$ at $37^{\circ} \mathrm{C}$. Cell pellets were harvested by centrifugation and suspended in a working buffer (50 mM NaH $\mathrm{mO}_{4}, \mathrm{pH} 8 \cdot 0,300 \mathrm{mM} \mathrm{NaCl}$ ) supplemented with $10 \mathrm{mM}$ imidazole (Sigma). Cells were lysed by incubation with $1 \mathrm{mg}$ lysozyme $\mathrm{ml}^{-1}$ (Sigma) on ice for $30 \mathrm{~min}$, followed by sonication. Cellular debris was removed by centrifugation, and the supernatant was loaded onto a column packed with nickel-nitrilotriacetic acid (Ni-NTA) affinity agarose (Qiagen). After extensive washing with the above working buffer supplemented with $20 \mathrm{mM}$ imidazole, the expressed proteins carrying a $6 \times$ His-Tag at the $\mathrm{N}$-terminus were eluted with the working buffer containing $250 \mathrm{mM}$ imidazole, according to the supplier's recommendations (Qiagen).

To express the IgG-binding receptor, exponential-phase cultures of BL21(DE3) carrying pETMig-Fc were incubated at $30{ }^{\circ} \mathrm{C}$ in the presence of $10 \mathrm{mM}$ glucose and carbenicillin, to maintain the resident plasmid. After $1 \mathrm{~h}$ incubation with $1 \mathrm{mM}$ IPTG, rifampicin was added, and induction was continued for $2.5 \mathrm{~h}$. Expressed protein was then purified as described for the $\alpha_{2}-\mathrm{M}$ receptors (above).

Preparation of streptococcal surface proteins. The search for B-IgA-binding receptors in $S$. dysgalactiae was carried out using cell-surface proteins extracted by three different methods. The enzymic method involved treating bacteria with mutanolysin (Sigma) to isolate $S$. dysgalactiae cell-wall fractions, in the presence of a protease inhibitor cocktail (Roche) (Kling et al., 1999; Song et al., 2001). The buffer method involved incubation of the bacteria in $50 \mathrm{mM}$ Tris buffer at different $\mathrm{pH}$ values $(7 \cdot 0,9 \cdot 0$ and $11 \cdot 0)$ overnight at $37^{\circ} \mathrm{C}$ before removing cells by centrifugation (Lindahl et al., 1990). The chemical method used cyanogen bromide (CNBr) (Sigma) to remove proteins from the cell surface by cleavage of methionine residues (Faulmann et al., 1991). Briefly, bacterial cultures were washed once in $0 \cdot 1 \mathrm{M}$ phosphate-buffered saline (PBS) and cell pellets were suspended in PBS. An equal volume of $\mathrm{CNBr}$ solution $\left(30 \mathrm{mg} \mathrm{CNBr} \mathrm{ml}^{-1}\right.$ in $0 \cdot 2 \mathrm{M} \mathrm{HCl}$ ) was added to bacterial suspensions to a final concentration of $15 \mathrm{mg}$ $\mathrm{CNBr} \mathrm{ml} \mathrm{m}^{-1}$. After overnight incubation at room temperature with end-to-end rotation, the supernatant was collected by centrifugation and sequentially washed twice in Ultrafree-15 Biomax-5 K protein concentrators (Millipore) with the following solutions: $0 \cdot 1 \mathrm{M} \mathrm{HCl}, 1 \mathrm{M}$ Tris $/ \mathrm{HCl}, \mathrm{pH} 8 \cdot 0$, and PBS.

Purification of B-slgA. Freshly collected bovine colostrum was centrifuged at $15000 \mathrm{~g}$ at $4{ }^{\circ} \mathrm{C}$ for $1.5 \mathrm{~h}$ to remove the top lipid layer. The clear middle layer was transferred to a clean centrifuge tube and centrifugation was repeated. The supernatant was treated with $2 \%$ glacial acetic acid to remove casein, and the solution was cleared by centrifugation at $15000 \mathrm{~g}$ at $4{ }^{\circ} \mathrm{C}$ for $1 \mathrm{~h}$. The supernatant was transferred into a clean tube and the $\mathrm{pH}$ neutralized with $\mathrm{NaOH}$. An equal volume of saturated $\left(\mathrm{NH}_{4}\right)_{2} \mathrm{SO}_{4}$ was added to the solution, and precipitated immunoglobulins were collected by centrifugation at $3000 \mathrm{~g}$ for $30 \mathrm{~min}$ at $4{ }^{\circ} \mathrm{C}$. The pellet was suspended in PBS and dialysed in a large volume of PBS at $4{ }^{\circ} \mathrm{C}$. To remove IgG from the B-sIgA preparation, the dialysed solution was passed three times through a Protein G-affinity column (MAbTrapGII, Pharmacia). The column flow-through portion was collected and washed twice in PBS with a Biomax-30 $\mathrm{K}$ protein concentrator (Millipore) prior to analysis.

Biotinylation of proteins. Prior to biotin coupling, $0.5-1 \mathrm{mg}$ of the purified proteins were equilibrated in $0.1 \mathrm{M} \mathrm{NaHCO}_{3}$ buffer at $\mathrm{pH} 8.0$ by centrifugation in a protein concentrator (Millipore). Labelling was initiated by adding $50 \mu \mathrm{g}$ biotin amidocaproate $\mathrm{N}$-hydroxysuccinate ester (Sigma) in DMSO (Sigma) to the samples and incubation was carried out for $1 \mathrm{~h}$ at room temperature with end-to-end mixing. Excess labelling solution was removed in a protein concentrator and concentrated proteins were equilibrated in PBS by two rounds of centrifugation in protein concentrators.

SDS-PAGE and Western blots. SDS-PAGE was performed according to the standard method (Sambrook et al., 1989). Gels were either stained with Coomassie brilliant blue or transferred onto nitrocellulose membranes (Bio-Rad). For Western blots, membranes were first blocked with PBS supplemented with $0.05 \%$ Tween 20 (PBS-T). Membranes were incubated for $2 \mathrm{~h}$ with either biotin-labelled proteins at a dilution between 1:250 and 1:500 and followed with APconjugated streptavidin (1:2000 dilution) (Life Technologies), or with the B-sIgA preparation at a dilution of $1: 250$ followed by 1:2000 diluted biotin-labelled second antibody and APconjugated streptavidin. The membranes were washed three times with PBS-T for $10 \mathrm{~min}$ between incubations. Blots were developed in AP buffer (100 mM NaCl, $5 \mathrm{mM} \mathrm{MgCl}$, $100 \mathrm{mM}$ Tris/ $\mathrm{HCl}, \mathrm{pH} 9.5$ ) supplemented with nitro blue tetrazolium and 5-bromo-4-chloro-3-indolyl phosphate (Sigma). Lowrange and high-range protein standards (Bio-Rad) were used to estimate the molecular mass of protein bands. The concentration of protein samples was determined on a microtitre plate with a DC Protein Assay kit and the Microplate Manager Software (Bio-Rad), using bovine serum albumin or IgG (Pierce) standards.

ELISA. Binding and binding-inhibition assays were performed in high-binding Immulon-2 U-bottom microtitre plates (Dynex Technologies). Each well was coated with $100 \mu \mathrm{l}$ of either purified Mig or B-IgA, at a concentration of $2 \mu \mathrm{g} \mathrm{ml}{ }^{-1}$, in $50 \mathrm{mM}$ sodium carbonate buffer ( $\mathrm{pH} \mathrm{9.6)} \mathrm{and} \mathrm{incubated}$ for $16 \mathrm{~h}$ at $4^{\circ} \mathrm{C}$. After four washes with TBST $(0 \cdot 1 \mathrm{M}$ Tris/ $\mathrm{HCl}, \mathrm{pH} 7 \cdot 5,0.17 \mathrm{M} \mathrm{NaCl}, 0.05 \%$ Tween 20), the wells were coated with $200 \mu \mathrm{l}$ TBSTg (TBST $+0.5 \%$ gelatin) for $16 \mathrm{~h}$ at $4{ }^{\circ} \mathrm{C}$ to block non-specific binding. After washing twice with TBST, $50 \mu \mathrm{l}$ of non-labelled inhibitor proteins, diluted in TBSTg at various concentrations, were added to each well and followed with $50 \mu \mathrm{l}$ of biotin-labelled B-IgA or Mig at a dilution of $1: 2000$. The reaction was performed at room temperature for $2 \mathrm{~h}$ and terminated by washing four times with TBSTg. Finally, plates were incubated with $100 \mu \mathrm{l}$ per well of AP-conjugated streptavidin diluted at 1:3000 for $1 \mathrm{~h}$ and developed with $p$-nitrophenyl phosphate (Sigma) in DE buffer $(0.1 \mathrm{M}$ diethanolamine, $0.5 \mathrm{M} \mathrm{MgCl}, 2 \mathrm{pH} 9.8)$ for $0 \cdot 5 \mathrm{~h}$. The absorbance was measured at $405 \mathrm{~nm}$ with a reference wavelength of $490 \mathrm{~nm}$ in a Bio-Rad 3550 microplate reader. The percentage of binding was calculated from the ratio of the absorbance in the wells containing the inhibitor proteins to the absorbance in wells without inhibitor proteins (100\% binding). The percentage of inhibition was calculated as 100 minus the percentage of binding. 
Determination of DNA sequences. The nucleotide sequences of constructed plasmids were determined on an ABI 373 DNA automatic sequencer (Applied Biosystems) at the Plant Biotechnology Institute (National Research Council, Saskatoon, SK, Canada). The sequence data were analysed with applications in the GCG software package (Wisconsin Package Version 10.1; Genetics Computer Group) and DNA-fold software (Michael Zuker, Washington University, St Louis, MO, USA) provided by the Canadian Bioinformatics Resources.

Determination of $\mathrm{N}$-terminal protein sequences. Prior to analysis, proteins expressed with the His-Tag system were pre-treated with thrombin protease (Novagen) to remove $\mathrm{N}$ terminal amino acid residues derived from the vector. After gel purification, the sample bands were transferred onto PVDF membranes (Millipore) by electro-blotting in a transfer buffer containing $10 \mathrm{mM}$ CAPS (pH 11) and $20 \%$ methanol. Samples were analysed either at the Victoria Protein Microchemistry Centre, University of Victoria, Victoria, BC, Canada, or at VIDO with a 490 Procise Protein Sequencer (Applied Biosystems).

\section{RESULTS}

\section{Expression of Mig and Mig-derived peptides}

The plasmids and bacterial strains constructed for this study as well as their Mig-related protein products are summarized in Fig. 1. The plasmid pETMig-3 expressed an $11 \mathrm{kDa}$ protein $\left(\alpha_{2}-\mathrm{M}-\mathrm{TR}\right)$, corresponding to a truncated form of the $\alpha_{2}-\mathrm{M}$ receptor contained within Mig. The complete $\alpha_{2}-\mathrm{M}$ receptor region of Mig $\left(\alpha_{2}-\mathrm{M}-\right.$ $\mathrm{R}$ ) is expressed by pETMig- 8 as a $17 \mathrm{kDa}$ product, while the IgG-binding domain is expressed by pETMig-Fc as a $39 \mathrm{kDa}$ protein. The plasmid p5Me expressed the mature form of Mig (Song et al., 2001). The bacterial strain Mig8-Mt expressed the $\alpha_{2}-\mathrm{M}-\mathrm{R}$ receptor, and since it lacks the Mig C-terminal anchor region this receptor was only found in the culture supernatants (Song et al., 2001). The strain Mig7-Mt is deficient in the expression of Mig on the cell surface (see below). The protein products expressed by the pET system contain 40 aa derived from the vector, in addition to the Migrelated peptides, resulting in protein products of approximately $16 \mathrm{kDa}$ for $\alpha_{2}-\mathrm{M}$-TR and approximately $22 \mathrm{kDa}$ for $\alpha_{2}-\mathrm{M}-\mathrm{R}$. As previously observed (Song et al., 2001), the relative mass of these protein products migrating in SDS-PAGE gels was larger than expected.

The purified products encoded by the plasmids pETMigFc, pETMig-8 and pETMig-3 were characterized by Western blotting. As expected, the $\alpha_{2}-\mathrm{M}-\mathrm{R}$ and $\alpha_{2}-\mathrm{M}-$ TR expressed by pETMig- 8 and pETMig-3, respectively, only reacted with anti-Mig polyclonal antibodies but not with the AP-conjugated IgG, whereas the IgG-R expressed by pETMig-Fc reacted with both antibodies (data not shown).

\section{Construction and characterization of the mig mutant strain}

To construct an isogenic mig mutant strain of $S$. dysgalactiae that did not express any part of Mig on the cell surface, a Sp-cassette was inserted immediately

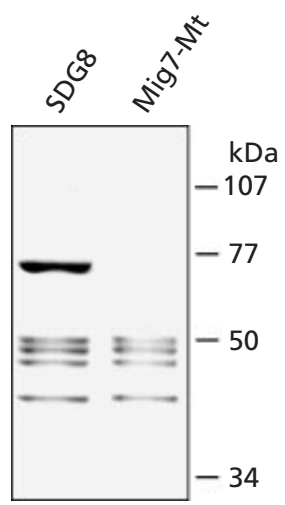

Fig. 2. CNBr preparations of the wild-type strain SDG8 and the mig mutant Mig7-Mt strain. Protein extracts were separated on an $8 \%$ SDS-PAGE gel, and stained with Coomassie blue.

downstream of the Mig start codon. The chromosomal map of the Mig7-Mt strain was analysed by Southern blots using probes specific to the mig IgG-binding region and to the Sp-cassette coding sequence. When the mig probe was used, a $2 \cdot 5 \mathrm{~kb}$ and a $2.0 \mathrm{~kb} H$ indIII fragment were detected in the SDG8 and Mig7-Mt genomic DNA, respectively (data not shown). The smaller size in the mig mutant strain was due to the introduction of a new HindIII site in the Sp-cassette (Fig. 1). With the Spcassette probe, no signal was found in the genomic DNA of SDG 8 whereas a $1.7 \mathrm{~kb}$ HindIII fragment was present in the mutant strain (data not shown), indicating that the $\mathrm{Sp}$-cassette has been inserted into the mig at the desired location.

The loss of Mig on the cell surface and in the culture supernatant of the Mig7-Mt strain was tested by Western blots. No signals were detected from cell wall and concentrated culture supernatant preparations by using either AP-conjugated goat anti-B-IgG or rabbit anti-Mig polyclonal antibodies followed by AP-conjugated goat anti-rabbit IgG (data not shown). We also examined a protein preparation of Mig7-Mt obtained by $\mathrm{CNBr}$ extraction. Coomassie-blue staining of the SDS-PAGE gel revealed that as with the previously constructed mig mutant strain Mig8-Mt (Song et al., 2001), only four protein bands were present in the $\mathrm{CNBr}$ extract of Mig7-Mt compared to the five bands present in the wild-type SDG8 strain (Fig. 2). These results indicated that the expression of Mig on the surface of the Mig7-Mt strain was abolished. We used $\mathrm{CNBr}$ to remove the IgG-binding proteins from the cell surface because it has been observed that these proteins generally lack internal methionine residues that are the specific cleavage site of CNBr (Faulmann \& Boyle, 1991). The extracted proteins therefore kept functional activities. N-terminal sequencing analyses were performed on all of the surface proteins extracted with $\mathrm{CNBr}$ from the wild-type SDG8 strain (Fig. 2). The sequence obtained of the $\mathrm{N}$-terminal region of the approximately $75 \mathrm{kDa}$ protein was ETIPAAVIVPVGLDTTE, matching residues 1-17 of the expected mature 


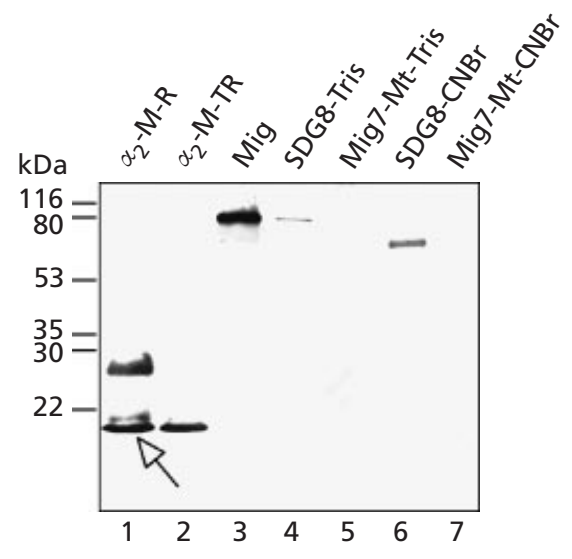

Fig. 3. Binding analyses of purified proteins and surfaceprotein preparations. The binding to biotin-labelled bovine serum IgA was analysed by Western blotting. Tris and $\mathrm{CNBr}$ indicate the method used to extract surface proteins from whole cells of the wild-type SDG8 and mig mutant Mig7-Mt strains. The purified $\alpha_{2}-M-R, \alpha_{2}-M-T R$ and Mig are expressed by pETMig-8, pETMig-3 and p5Me, respectively. The band indicated by an arrow was further characterized by $\mathrm{N}$-terminal protein sequencing (see text for details).

Mig protein, and indicating that the approximately $75 \mathrm{kDa}$ product obtained by $\mathrm{CNBr}$ extraction was indeed Mig. We did not find sequence homology to Mig in any of the remaining four bands from the SDG8 strain, indicating that these four proteins were not degradation products of Mig. However, some of them exhibited homology to M1 and extracellular matrixbinding proteins of S. pyogenes (data not shown).

\section{Binding activities of Mig and B-IgA analysed by Western blots}

To examine and characterize B-IgA-binding receptors in S. dysgalactiae, commercial B-IgA was used as a probe in Western blots. Since many IgA-binding receptors in $S$. pyogenes also exhibit IgG-binding activities (Stenberg et al., 1994) that may cause non-specific reactions with the second conjugated antibodies, we employed a direct testing approach by labelling B-IgA with biotin and used it to test B-IgA-binding receptors followed by APconjugated streptavidin and AP substrates as detection systems. The reaction background with the AP-conjugated streptavidin was found to be negligible in all cases.

We tested surface protein preparations extracted by each of three different methods (see Methods). Proteins extracted from whole SDG8 cells by enzymic (data not shown) or buffer treatments resulted in an approximately $80 \mathrm{kDa}$ band that co-migrated with the purified recombinant Mig; both of these bound B-IgA (Fig. 3, lanes 4 and 3, respectively). The approximately $75 \mathrm{kDa}$ Mig-derived protein obtained by $\mathrm{CNBr}$ extraction (Fig. 2) was also able to bind B-IgA (Fig. 3, lane 6). The difference in molecular mass of Mig extracted by the $\mathrm{CNBr}$ method and the buffer method was probably due to the nature of $\mathrm{CNBr}$ cleavage, which occurs at the C- terminal side of methionine residues. Upon inspection of the deduced protein sequence of Mig, we found a methionine residue at position 615 of the mature Mig protein (Song et al., 2001). CNBr cleavage at this position would result in a mature peptide of 614 residues, with an estimated molecular mass of approximately $67 \mathrm{kDa}$. Taking into consideration the aberrant migration of these proteins on SDS-PAGE gels, the approximately $75 \mathrm{kDa}$ protein observed on the SDG8 $\mathrm{CNBr}$ extract is consistent with the expected size of the $\mathrm{CNBr}$-derived peptide of Mig.

To confirm the specific binding of Mig and labelled B$\operatorname{IgA}$, the recombinant Mig protein and the constructed isogenic mig mutant strains were tested. As expected, the recombinant Mig protein bound labelled B-IgA (Fig. 3 , lane 3) whereas no binding was found in the bufferand $\mathrm{CNBr}$-preparations of the mig mutant strains Mig8Mt (data not shown) and Mig7-Mt (Fig. 3, lanes 5 and 7, respectively). Surface protein preparations from $S$. pyogenes M5 Manfredo and S. agalactiae strain SB35, both of which express $\mathrm{H}-\operatorname{Ig} \mathrm{A}-$ binding receptors, were included as controls. Neither preparation contained proteins able to bind B-IgA (data not shown). These results also suggested that the B-IgA-binding receptor present in $S$. dysgalactiae is different from the extensively studied H-IgA-binding receptor of other streptococci.

The binding of Mig to B-IgA was also characterized by using biotin-labelled Mig to detect immobilized B-IgA by Western blots. High-molecular-mass protein bands binding to labelled Mig were detected when proteins were separated in a $6 \%$ polyacrylamide gel under nonreducing conditions (data not shown). In contrast, immobilized $\mathrm{H}-\operatorname{Ig} \mathrm{A}$ and $\mathrm{B}-\operatorname{IgM}$ did not exhibit any binding activities to the labelled Mig (data not shown).

We extended our study to analyse binding of Mig to the secretory form of $\operatorname{IgA}$ (B-sIgA) obtained from bovine colostrum. Prior to analysis, the partially purified BsIgA preparation was characterized with antibodies against B-sIgA and B-IgG in Western blots. Under nonreducing conditions, high-molecular-mass bands were found in the B-sIgA preparation reacting with the rabbit anti-B-sIgA followed by AP-conjugated goat anti-rabbit $\operatorname{IgG}$ (data not shown). However, there was no reaction with the conjugated goat anti-B-IgG (data not shown). The results suggested that the B-sIgA preparation contains detectable amounts of $\mathrm{B}-\operatorname{sig} \mathrm{A}$ and that it is free of IgG. However, when the membrane-immobilized B-sIgA was tested with biotin-labelled Mig, we did not detect binding (data not shown). In a reciprocal analysis, the ability of soluble B-sIgA to bind immobilized Mig and Mig-derived peptides was analysed using biotin-labelled rabbit anti-B-sIgA as the second antibody. As expected, the recombinant Mig protein showed binding. This was probably due in part to the IgG receptor binding to the secondary antibody, and in part to the $\alpha_{2}-\mathrm{M}$ receptors of Mig binding to the B-sIgA. In the same experiment, the immobilized recombinant $\alpha_{2}-$ $\mathrm{M}$ receptor also showed binding to B-sIgA (data not shown). This indicated that soluble B-sIgA binds the immobilized $\alpha_{2}$-M-binding receptor of Mig. 

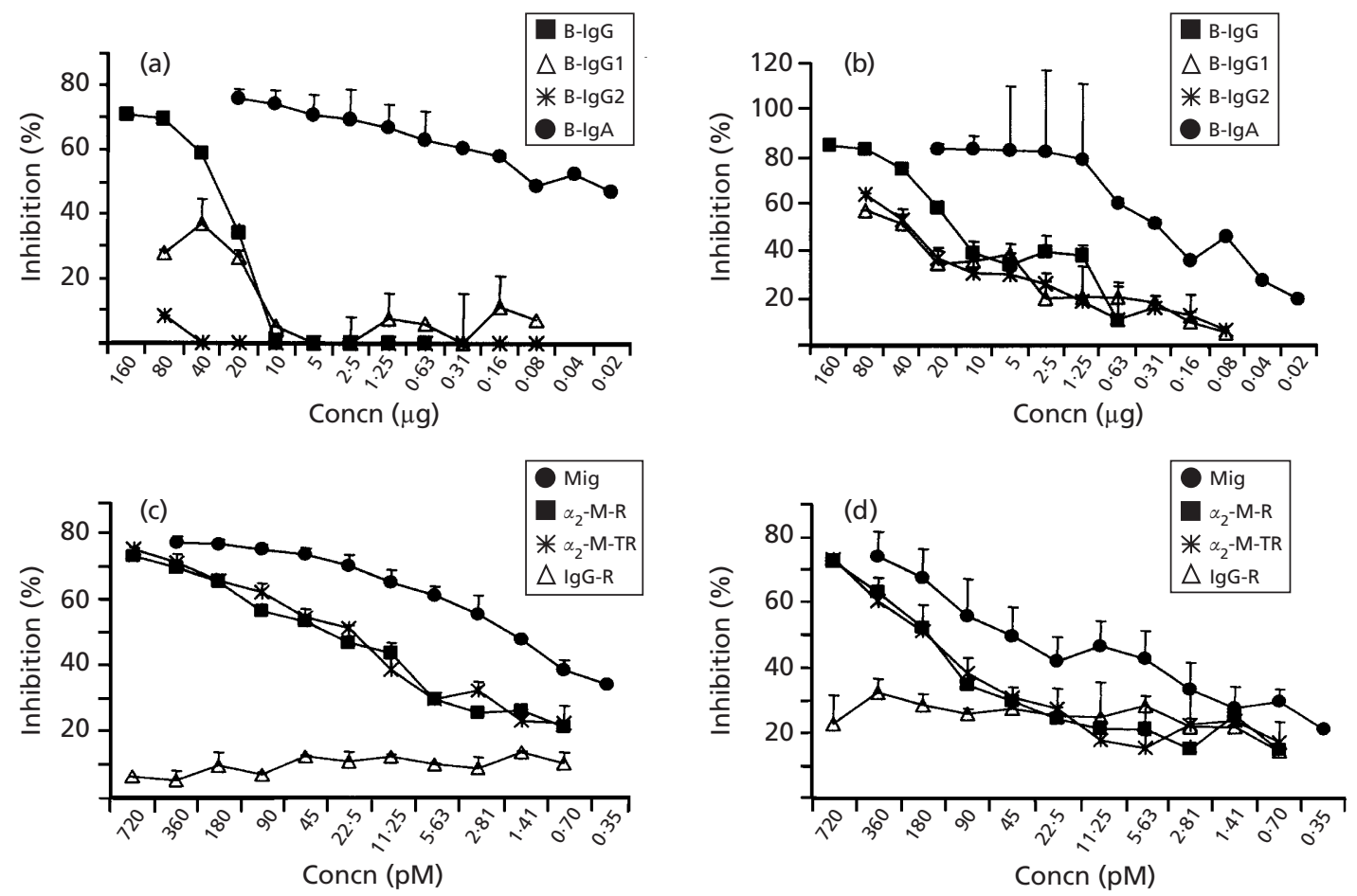

Fig. 4. Binding-inhibition assays. $(a, c)$ Bovine serum IgA-coated microtitre plates incubated with biotin-labelled Mig in the presence of different concentrations of (a) B-lgG, B-lgG,$B-\lg G_{2}$ and bovine serum $\lg A$, or (c) Mig and Mig-derived $\alpha_{-} \mathrm{M}-\mathrm{R}, \alpha_{2}-\mathrm{M}-\mathrm{TR}$ and IgG-R proteins. $(b, d)$ Mig-coated microtitre plates incubated with biotin-labelled B-lgA in the presence of different concentrations of (b) B-IgG, B-lgG,$B-\lg G_{2}$ and B-IgA, or (d) Mig and Mig-derived $\alpha_{2}-\mathrm{M}-\mathrm{R}, \alpha_{2}-\mathrm{M}-\mathrm{TR}$ and IgG-R proteins. Each point represents the mean \pm SD of values obtained from four experiments.

\section{Localization of B-IgA-binding-domains in Mig}

To identify the B-IgA-binding domains of Mig, purified $\alpha_{2}-\mathrm{M}$ and $\operatorname{IgG}$ receptors were tested with labelled B-IgA in Western blots. The $\alpha_{2}-\mathrm{M}-\mathrm{R}$ receptor expressed by pETMig- 8 contained two protein products that bound B-IgA (Fig. 3, lane 1) but not IgG (data not shown), which were the expected approximately $22 \mathrm{kDa} \alpha_{2}-\mathrm{M}-\mathrm{R}$ receptor and a band migrating at approximately $16 \mathrm{kDa}$. To characterize this additional band in the $\alpha_{2}-\mathrm{M}-\mathrm{R}$ preparation, N-terminal protein sequencing was performed on the gel-purified protein pre-treated with thrombin protease to remove the $\mathrm{N}$-terminal amino acid residues encoded by vector DNA. The sequence of the first 10 aa of the insert was determined to be PVGLDTTELQ, matching the predicted $\mathrm{N}$-terminal sequence of $\alpha_{2}-\mathrm{M}-\mathrm{R}$ expressed by pETMig- 8 . This indicated that the smaller peptide in the $\alpha_{2}$-M-R preparation is the result of a truncated $\alpha_{2}-\mathrm{M}$ receptor, probably arising from premature termination of transcription due to a large branched hairpin structure within the $\alpha_{2}-\mathrm{M}$ coding region, with a free energy of $-48 \cdot 6 \mathrm{kcal} \mathrm{mol}^{-1}(-203 \cdot 3$ $\mathrm{kJ} \mathrm{mol}{ }^{-1}$ ) as predicted by the DNA-fold software (data not shown).

The $\alpha_{2}$-M-TR protein expressed by pETMig-3 (Fig. 1) is a truncated $\alpha_{2}-\mathrm{M}$ receptor carrying the N-terminal $11 \mathrm{kDa}$ region of Mig. This protein migrated at the same position as the smaller peptide expressed by pETMig-8, and bound labelled B-IgA but not IgG (Fig. 3, lane 2). This observation suggested that the B-IgA-binding receptor was located in the $\mathrm{N}$-terminal $11 \mathrm{kDa}$ region of Mig. This hypothesis was further strengthened by the finding that a 29 aa sequence, postulated to be a conserved binding domain to $\mathrm{H}$-IgA in S. pyogenes (Johnsson et al., 1994), revealed $54 \%$ similarity and $46 \%$ identity to a region in the $\alpha_{2}$-M-TR receptor (data not shown). Although these two proteins bind different species of IgA, a sequence or structure homology may exist among these IgA-binding receptors. The Mig Fc receptor encoded by pETMig-Fc bound only conjugated IgG but not B-IgA (Fig. 1), confirming that the B-IgAbinding receptor is located in the $\alpha_{2}-\mathrm{M}$-binding region.

\section{Binding inhibition analysis by ELISA}

Either B-IgA or Mig was used to coat microtitre plates, and binding assays were performed with either biotinlabelled Mig or biotin-labelled B-IgA. Unlabelled immunoglobulins, Mig and Mig-derived proteins were tested as inhibitors. On the B-IgA coated plates, the binding of Mig to B-IgA was inhibited by B-IgA, Mig, $\alpha_{2}-\mathrm{M}-\mathrm{R}$ and $\alpha_{2}-\mathrm{M}-\mathrm{TR}$ receptors, but not by $\mathrm{B}-\mathrm{IgG} \mathrm{G}_{1}$, B-IgG ${ }_{2}$ or the Mig-IgG receptor expressed by pETMigFc (Fig. 4a, c). A similar result was obtained when B-IgA was tested on the Mig-coated plates (Fig. 4b, d). 
A noteworthy phenomenon was that the bindinginhibition effects of the intact and truncated $\alpha_{2}-\mathrm{M}$ receptors were comparable to each other, whereas both were lower than that of the complete Mig protein (Fig. 4c, d). This suggests that although the $\alpha_{2}-\mathrm{M}-\mathrm{TR}$ $11 \mathrm{kDa}$ N-terminal fragment of Mig contains the B-IgAbinding receptor, a whole Mig protein might be required for a full binding activity, which is probably due to differences in the secondary structures between these proteins.

\section{DISCUSSION}

Most pathogenic bacteria and viruses use mucosal pathways such as the oral, intestinal and mammary gland as their port of entry for invasion into their host. In the case of the bovine mammary gland, immunoglobulins are one of several active defence mechanisms for protection of the gland from bacterial infections. The concentration of the immunoglobulin classes varies with the stage of lactation and health of the mammary gland. In colostrum, and in secretions obtained from dry animals, the concentration of $\operatorname{Ig} \mathrm{A}$ increases considerably with respect to the IgA levels in milk (International Dairy Federation, 2000; Sordillo et al., 1997), while in inflamed udders, there is also an increase in the levels of $\operatorname{IgA}$, suggesting passive transfer from the serum to the mammary secretions (Guidry et al., 1980). These higher levels of IgA in mammary secretions could serve as a first line of protection against a pathogen. Several pathogenic Gram-positive bacteria encode surface proteins capable of binding to immunoglobulins, and it is postulated that this binding might help the bacterium to evade the immunological surveillance of the host. Surface proteins encoding IgA-binding receptors have been reported in $S$. pneumoniae, and streptococcal strains of groups A and $\mathrm{B}$, but these proteins specifically bind only H-IgA (Bessen, 1994; Cleat \& Timmis, 1987; Fagan et al., 2001; Hammerschmidt et al., 1997; Hedén et al., 1991; Johnsson et al., 1994; Russell-Jones et al., 1984; Serhir et al., 1995; Stenberg et al., 1994). Since IgA-binding receptors might play a role in bacterial pathogenesis, we were interested in examining the existence of B-IgAbinding receptors in $S$. dysgalactiae, an environmental pathogen that can infect and cause subsequent inflammation of the bovine mammary gland.

Among surface protein preparations, an approximately $80 \mathrm{kDa}$ band extracted by the enzyme and buffer methods, and an approximately $75 \mathrm{kDa}$ band extracted by the CNBr method from the wild-type SDG8 strain, were found to bind labelled B-IgA. In contrast, these bands were absent in the same preparations of the isogenic mig mutant strains Mig8-Mt (data not shown) and Mig7-Mt (Fig. 3), suggesting that both the $80 \mathrm{kDa}$ and the $75 \mathrm{kDa} \mathrm{B}-\mathrm{IgA}$-binding proteins were Mig or a Mig-derived protein. The $80 \mathrm{kDa}$ protein bands migrated at the same size in the gel and displayed similar binding activities to the purified recombinant Mig protein in reactions with IgG and anti-Mig antibodies, indicating that the approximately $80 \mathrm{kDa}$ B-IgA-binding protein extracted by the enzyme and buffer methods is the mature Mig protein. The use of the $\mathrm{CNBr}$ extraction method was based on the previous observations that type II (Otten et al., 1992; Raeder et al., 1992) and type III (Hedén et al., 1991) IgG-binding receptors of streptococci were efficiently solubilized with $\mathrm{CNBr}$. Because of a shortage of internal methionine residues in these IgG-binding receptors, the extracted proteins still exhibit biological functions. We therefore applied this method to extract Mig, a type III IgG-binding receptor (Jonsson \& Müller, 1994), and other surface proteins from $S$. dysgalactiae strains. The approximately $75 \mathrm{kDa}$ B-IgA-binding protein in the CNBr extract of the SDG8 strain displayed similar antibody-binding activities (data not shown) to purified Mig, although the size was a little smaller than the native protein. We postulate that the smaller size of the CNBr-extracted Mig (approx. $75 \mathrm{kDa}$ ) is due to the cleavage of a methionine residue by $\mathrm{CNBr}$ in the C-terminal region of $\mathrm{Mig}$, because the $\mathrm{N}$ terminal sequence of the $75 \mathrm{kDa}$ protein was identical to the $\mathrm{N}$-terminal sequence of the mature Mig protein determined in our protein sequence analysis.

To identify the B-IgA-binding domains in Mig, the ability of Mig-derived recombinant $\alpha_{2}-\mathrm{M}$ and $\operatorname{IgG}$ receptors to bind labelled B-IgA was tested. Both intact and truncated $\alpha_{2}-\mathrm{M}$ receptors, expressed from pETMig8 and pETMig-3, respectively, bound B-IgA (Fig. 3, lanes 1 and 2), whereas no binding to B-IgA was observed with the IgG receptor expressed by pETMig-Fc (data not shown). Both forms of the $\alpha_{2}-\mathrm{M}$ receptors also exhibited specific inhibition of the binding of labelled B$\operatorname{IgA}$ and Mig, and vice versa (Fig. 4c, d), indicating that the $\mathrm{B}-\mathrm{IgA}$-binding region is located within the truncated form of $\alpha_{2}-\mathrm{M}$ receptor corresponding to the $\mathrm{N}$-terminal $11 \mathrm{kDa}$ region of Mig. Furthermore, we also analysed BIgA-binding activities in concentrated cell culture supernatants of two mig mutant strains. Due to difference in the $\mathrm{Sp}$-cassette insertion site, the Mig8-Mt expressed a $28 \mathrm{kDa}$ peptide containing the $\alpha_{2}-\mathrm{M}$ receptor into the culture supernatant (Song et al., 2001), whereas the Mig7-Mt constructed in this study entirely lost the expression of Mig. As expected, the $28 \mathrm{kDa}$ peptide expressed by Mig8-Mt bound B-IgA but no binding proteins were found in the Mig7-Mt preparations (data not shown). This observation further confirmed our finding that the B-IgA-binding domain of Mig was located at the $\mathrm{N}$-terminal $\alpha_{2}$-M-binding region.

Potential conserved $\mathrm{H}-\mathrm{IgA}$ receptor sequences have been described and tested in a few studies in streptococcal species. These include the 29 and 50 aa peptides derived from the S. pyogenes Arp4 (Johnsson et al., 1994) and Sir22 proteins (Johnsson et al., 1999), respectively. Also tested were the protein motifs ALXGENXDLR from the S. pyogenes Arp4 and ML2.2 proteins (Bessen, 1994), MLKKIE derived from the $\beta$-antigen of the $\mathrm{c}$ protein complex of group B S. agalactiae (Jerlström et al., 1996), and YRNYPT from S. pneumoniae (Hammerschmidt et al., 2000). However, only the 50 aa peptide derived from the $S$. pyogenes Sir22 protein exhibited functional activities in its isolated form (Johnsson et al., 1999). These proteins are species-specific H-IgA-binding recep- 
tors. However, the 29 conserved residues that were derived from the S. pyogenes Arp4 protein (Johnsson et al., 1994) shared about $50 \%$ homology with the deduced Mig protein sequence (data not shown). This homologous region was located within the $11 \mathrm{kDa} \alpha_{2}$-M-TR region, which is in agreement with the observation that the $11 \mathrm{kDa} \alpha_{2}$-M-TR peptide blocked the binding activities between Mig and B-IgA in our binding assays (Fig. 4). Although the specific B-IgA-binding sequences have yet to be identified in Mig, the sequence similarity between $\mathrm{H}$-IgA- and B-IgA-binding receptors suggests that there might be some common features shared among them. Currently, we are investigating some other B-IgA-binding proteins with divergent plasma-proteinbinding profiles in different $S$. dysgalactiae strains. The sequence data of these studies will enable us to identify conserved B-IgA-binding peptide sequences. However, the sequences or regions responsible for the full B-IgAbinding activities might depend on the conformation of a larger region or whole molecule. This speculation is based on our binding inhibition assay result that the whole Mig protein had a higher inhibitory effect than the $\alpha_{2}-\mathrm{M}$ receptors at the same concentration (Fig. $4 \mathrm{c}, \mathrm{d}$ ). This finding is similar to the cooperative activities of five IgG-binding repeats in binding to IgG (Vasi et al., 1999).

Among streptococcal H-IgA-binding proteins, the group A streptococcal receptors bind both serum IgA and sIgA, the group B streptococcal receptor mainly binds serum $\operatorname{IgA}$, and S. pneumoniae receptors only bind the $\operatorname{IgA}$ secretory component (SC) region (Hammerschmidt et al., 2000). Probably due to the binding activities to sIgA, the group A streptococcal IgA-binding receptors might be involved in anti-phagocytic activities, and a few studies have suggested that binding to IgA interfered with interactions between bacteria and host cells (Fluckiger et al., 1998). Since $\operatorname{IgA}$ is the predominant immunoglobulin defence against microbial infection of human mucosal surfaces, sequestering of $\operatorname{IgA}$ by the bacterium may be a mechanism for avoiding the first line of host defence. The binding to IgA might also block the interactions between the IgA Fc part and the host receptors (Johnsson et al., 1999). In our work, when BsIgA was immobilized on the membrane, no binding activities were found to labelled Mig. However, when Mig was immobilized on the membrane and tested with soluble B-sIgA, the purified $\alpha_{2}-\mathrm{M}$ receptors of Mig bound B-sIgA (data not shown). This observation is in contradiction to previous studies, where soluble $\mathrm{H}$-sIgA displayed a much lower binding activity than the immobilized H-sIgA to the streptococcal group B receptor; probably due to the fact that the SC molecule interferes with binding to that type of receptor (Faulmann \& Boyle, 1991; Faulmann et al., 1991; Lindahl \& Stenberg, 1990). Although the binding activities of Mig and B-sIgA have to be further characterized, our data suggest that binding of Mig to B-sIgA might be different from the interaction of human streptococcal pathogens with H-sIgA.

The Mig protein of $S$. dysgalactiae expresses $\alpha_{2}-\mathrm{M}$ and IgG-binding receptors (Jonsson \& Müller, 1994), and is involved in resistance to phagocytosis (Song et al., 2001). Here we report that Mig also binds B-IgA and B-sIgA. S. dysgalactiae infects cows in the dry period when the IgA levels in the mammary secretions are higher, and is capable of adhering, colonizing, invading and surviving inside bovine mammary gland epithelial cells (Calvinho \& Oliver, 1998). Binding to B-IgA and B-sIgA by $S$. dysgalactiae may mask the bacteria, allowing avoidance of the first line of host defence. The factors of $S$. dysgalactiae involved in the invasion of MAC-T cells by a receptor-mediated endocytosis mechanism remain undetermined (Calvinho \& Oliver, 1998). Thus, it is conceivable that the IgA receptor on the MAC-T cell surface binds to IgA-covered $S$. dysgalactiae cells, allowing the bacterium to be internalized into the epithelial cell. Experiments are being carried out to investigate the role of $\mathrm{B}-\operatorname{sig} \mathrm{A}$ and $\mathrm{B}-\operatorname{Ig} \mathrm{A}$ in the interaction of $S$. dysgalactiae with mammary gland host cells.

Cleary \& Retnoningrum (1994) proposed a very exciting role for immunoglobulin-binding proteins of streptococci. These authors suggested that by binding to different immunoglobulins, streptococci encoding $\mathrm{M}$ like proteins might be able to act as macromolecules that distinguish specific tissues or fluids in the body. In the case of Mig, this protein could act as the sensory component of a multiple component system whereby binding of IgG and/or IgA to Mig could trigger a conformational change on this protein resulting in the activation of secondary proteins with histidine-kinase activities that result in modulation of gene expression of factors involved in virulence.

\section{ACKNOWLEDGEMENTS}

We thank Ms T. Prysliak for her invaluable assistance, Dr P. Willson for helpful discussions, Mrs D. Dent for providing immunoglobulins, and Dr S. Attah-Poku and Mr W. Deck for protein sequencing.

This work was supported by The Natural Sciences and Engineering Research Council of Canada, Canadian Bacterial Diseases Network, Saskatchewan Agriculture Development Fund, and The Dairy Farmers of Canada.

This paper is published with permission of the Director of VIDO as journal series no. 309.

\section{REFERENCES}

Bessen, D. E. (1994). Localization of immunoglobulin A-binding sites within $\mathrm{M}$ or $\mathrm{M}$-like proteins of group A streptococci. Infect Immun 62, 1968-1974.

Calvinho, L. F. \& Oliver, S. P. (1998). Characterization of mechanisms involved in uptake of Streptococcus dysgalactiae by bovine mammary epithelial cells. Vet Microbiol 63, 261-274.

Calvinho, L. F., Almeida, R. A. \& Oliver, S. P. (1998). Potential virulence factors of Streptococcus dysgalactiae associated with bovine mastitis. Vet Microbiol 61, 93-110.

Cleary, P. \& Retnoningrum, D. (1994). Group A streptococcal immunoglobulin-binding proteins: adhesins, molecular mimicry or sensory proteins? Trends Microbiol 2, 131-136.

Cleat, P. H. \& Timmis, K. N. (1987). Cloning and expression in Escherichia coli of the Ibc protein genes of group B streptococci: 
binding of human immunoglobulin A to the beta antigen. Infect Immun 55, 1151-1155.

Fagan, P. K., Reinscheid, D., Gottschalk, B. \& Chhatwal, G. S. (2001). Identification and characterization of a novel secreted immunoglobulin binding protein from group A streptococcus. Infect Immun 69, 4851-4857.

Faulmann, E. L. \& Boyle, M. D. (1991). A simple preparative procedure to extract and purify protein $G$ from group $G$ streptococci. Prep Biochem 21, 75-86.

Faulmann, E. L., Duvall, J. L. \& Boyle, M. D. (1991). Protein B: a versatile bacterial $\mathrm{Fc}$-binding protein selective for human IgA. Biotechniques 10, 748-755.

Fluckiger, U., Jones, K. F. \& Fischetti, V. A. (1998). Immunoglobulins to group A streptococcal surface molecules decrease adherence to and invasion of human pharyngeal cells. Infect Immun 66, 974-979.

Guidry, A. J., Paape, M. J. \& Pearson, R. E. (1980). Effect of udder inflammation on milk immunoglobulins and phagocytosis. Am J Vet Res 41, 751-753.

Hammerschmidt, S., Talay, S. R., Brandtzaeg, P. \& Chhatwal, G. S. (1997). SpsA, a novel pneumococcal surface protein with specific binding to secretory immunoglobulin A and secretory component. Mol Microbiol 25, 1113-1124.

Hammerschmidt, S., Tillig, M. P., Wolff, S., Vaerman, J.P. \& Chhatwal, G. S. (2000). Species-specific binding of human secretory component to SpsA protein of Streptococcus pneumoniae via a hexapeptide motif. Mol Microbiol 36, 726-736.

Hedén, L.-O., Frithz, E. \& Lindahl, G. (1991). Molecular characterization of an IgA receptor from group B streptococci: sequence of the gene, identification of a proline-rich region with unique structure and isolation of $\mathrm{N}$-terminal fragments with IgA-binding capacity. Eur J Immunol 21, 1481-1490.

International Dairy Federation (2000). IDF Position Paper on ruminant mammary gland immunity. In Symposium on Immunology of Ruminant Mammary Gland, pp. 1-91. Edited by A. Zecconi \& K. L. Smith. Stressa.

Jerlström, P. G., Talay, S. R., Valentin-Weigand, P., Timmis, K. N. \& Chhatwal, G. S. (1996). Identification of an immunoglobulin A binding motif located in the $\beta$-antigen of the c protein complex of group B streptococci. Infect Immun 64, 2787-2793.

Johnsson, E., Andersson, G., Lindahl, G. \& Hedén, L.-O. (1994). Identification of the IgA-binding region in streptococcal protein Arp. J Immunol 153, 3557-3564.

Johnsson, E., Areschoug, T., Mestecky, J. \& Lindahl, G. (1999). An IgA-binding peptide derived from a streptococcal surface protein. J Biol Chem 274, 14521-14524.

Jonsson, H. \& Müller, H.-P. (1994). The type-III Fc receptor from Streptococcus dysgalactiae is also an $\alpha_{2}$-macroglobulin receptor. Eur J Biochem 220, 819-826.

Jonsson, H., Frykberg, L., Rantamäki, L. \& Guss, B. (1994). MAG, a novel plasma protein receptor from Streptococcus dysgalactiae. Gene 143, 85-89.

Kling, D. E., Madoff, L. C. \& Michel, J. L. (1999). Subcellular fractionation of group B Streptococcus. Biotechniques 27, 24-28.
Kurien, B. T. \& Scofield, R. H. (1995). Polyethylene glycolmediated bacterial colony transformation. BioTechniques 18, 1023-1026.

Lindahl, G. \& Åkerström, B. (1989). Receptor for IgA in group A streptococci: cloning of the gene and characterization of the protein expressed in Escherichia coli. Mol Microbiol 3, 239-247.

Lindahl, G. \& Stenberg, L. (1990). Binding of IgA and/or IgG is a common property among clinical isolates of group A streptococci. Epidemiol Infect 105, 87-93.

Lindahl, G., Åkerström, B., Vaerman, J.-P. \& Stenberg, L. (1990). Characterization of an IgA receptor from group B streptococci: specificity for serum IgA. Eur J Immunol 20, 2241-2247.

Otten, R. A., Raeder, R., Heath, D. G., Lottenberg, R., Cleary, P. P. \& Boyle, M. D. P. (1992). Identification of two type IIa IgGbinding proteins expressed by a single group A streptococcus. $J$ Immunol 148, 3174-3182.

Perez-Casal, J., Price, J. A., Maguin, E. \& Scott, J. R. (1993). An M protein with a single $C$ repeat prevents phagocytosis of Streptococcus pyogenes: use of a temperature-sensitive shuttle vector to deliver homologous sequences to the chromosome of $S$. pyogenes. Mol Microbiol 8, 809-819.

Raeder, R., Otten, R. A., Chamberlin, L. \& Boyle, M. D. P. (1992). Functional and serological analysis of type II immunoglobulin Gbinding proteins expressed by pathogenic group A streptococci. $J$ Clin Microbiol 30, 3074-3081.

Russell-Jones, G. J., Gotschlich, E. C. \& Blake, M. S. (1984). A surface receptor specific for human IgA on group B streptococci possessing the Ibc protein antigen. J Exp Med 160, 1467-1475.

Sambrook, J., Fritsch, E. F. \& Maniatis, T. (1989). Molecular Cloning: a Laboratory Manual, 2nd edn. Cold Spring Harbor, NY : Cold Spring Harbor Laboratory.

Serhir, B., Dubreuil, D., Higgins, R. \& Jacques, M. (1995). Purification and characterization of a 52-kilodalton immunoglobulin G-binding protein from Streptococcus suis capsular type 2. J Bacteriol 177, 3830-3836.

Song, X.-M., Perez-Casal, J., Bolton, A. \& Potter, A. A. (2001). Surface-expressed Mig protein protects Streptococcus dysgalactiae against phagocytosis by bovine neutrophils. Infect Immun 69, 6030-6037.

Sordillo, L. M., Shafer-Weaver, K. \& DeRosa, D. (1997). Immunobiology of the mammary gland. J Dairy Sci 80, 1851-1865.

Stenberg, L., O'Toole, P. W., Mestecky, J. \& Lindahl, G. (1994). Molecular characterization of protein Sir, a streptococcal cell surface protein that binds both immunoglobulin A and immunoglobulin G. J Biol Chem 269, 13458-13464.

Vasi, J., Svensson, J., Frick, I.-M. \& Müller, H.-P. (1999). Five homologous repeats of the protein G-related protein MIG cooperate in binding to goat immunoglobulin G. Infect Immun 67, 413-416.

Vasi, J., Frykberg, L., Carlsson, L. E., Lindberg, M. \& Guss, B. (2000). M-like proteins of Streptococcus dysgalactiae. Infect Immun 68, 294-302.

Received 10 December 2001; revised 21 February 2002; accepted 4 March 2002. 